\title{
Extensive mitochondrial proteome disturbance occurs during the early stages of acute myocardial ischemia
}

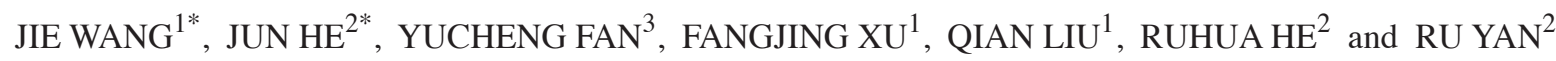 \\ ${ }^{1}$ School of Clinical Medicine, Ningxia Medical University; \\ ${ }^{2}$ Department of Cardiovascular Internal Medicine, General Hospital of Ningxia Medical University; \\ ${ }^{3}$ School of Basic Medicine, Ningxia Medical University, Yinchuan, Ningxia 750004, P.R China
}

Received July 23, 2021; Accepted November 5, 2021

DOI: $10.3892 /$ etm.2021.11008

\begin{abstract}
Mitochondrial malfunction leads to the remodeling of myocardial energy metabolism during myocardial ischemia (MI). However, the alterations to the mitochondrial proteome profile during this period has not yet been clarified. An acute MI model was established by high position ligation of the left anterior descending artery in 8-week-old C57BL/6N mice. After 15 min of ligation, the animals were euthanized, and their hearts were collected. The myocardial ultrastructure was observed using transmission electron microscopy (TEM). The cardiac mitochondrial proteome profile was analyzed by liquid chromatography-tandem mass spectrometry (LC-MS/MS)
\end{abstract}

Correspondence to: Dr Jun He, Department of Cardiovascular Internal Medicine, General Hospital of Ningxia Medical University, Building 10, 804 Shengli Street, Yinchuan, Ningxia 750004, P.R. China E-mail: junhe@nxmu.edu.cn

${ }^{*}$ Contributed equally

Abbreviations: MI, myocardial ischemia; LC-MS/MS, liquid chromatography-tandem mass spectrometry; LAD, left anterior descending artery; OXPHOS, oxidative phosphorylation; TEM, transmission electron microscopy; PBS, phosphate-buffered saline; BCA, bicinchoninic acid; MMP, mitochondria membrane potential; UPLC system, ultra-performance LC system; PCA, principal component analysis; GO, Gene Ontology; KEGG, Kyoto Encyclopedia of Genes and Genomes; FC, fold change; VDAC1, voltage-dependent anion-selective channel protein 1; PDPR, pyruvate dehydrogenase phosphatase regulatory subunit; NDUFS6, NADH dehydrogenase (ubiquinone) iron-sulfur protein 6; UQCRC1, cytochrome b-c1 complex subunit 1; THBS1, thrombospondin-1; DCTN2, dynactin subunit 2; AKAP1, a-kinase anchor protein 1; COX, cytochrome C oxidase; ATP, adenosine triphosphate; ATP5G2, ATP synthase $\mathrm{F}(0)$ complex subunit C2; MUL1, mitochondria ubiquitin ligase activator of NF- $\mathrm{BB} 1$; PPAR, peroxisome proliferator-activated receptor; HIF-1, hypoxia-inducible factor-1; ROS, reactive oxygen species; PRKAR2 $\alpha$, cAMP-dependent protein kinase type II- $\alpha$ regulatory subunit; AKAP1, A-kinase anchor protein 1, mitochondrial; JPH2, Junctophilin-2

Key words: acute myocardial ischemia, mitochondria, proteome, myocardial remodeling, liquid chromatography-tandem mass spectrometry and bioinformatics analyses. TEM showed that the outer membrane of the mitochondria was dissolved, and the inner membrane (cristae) was corrupted and broken down extensively in the MI group. The mitochondrial membrane potential was decreased. More than 1,700 mitochondrial proteins were identified by LC-MS/MS analysis, and 119 were differentially expressed. Gene Ontology and the Kyoto Encyclopedia of Genes and Genomes functional enrichment analysis showed that endopeptidase activity regulation, the mitochondrial inner membrane, oxidative phosphorylation, the hypoxia-inducible factor-1 signaling pathway, the pentose phosphate pathway and the peroxisome proliferator-activated receptor signaling pathway were involved in the pathophysiological process in the early stage of acute MI. Extensive and substantial changes in the mitochondrial proteins as well as mitochondrial microstructural damage occur in the early stages of acute MI. In the present study, the series of proteins crucially involved in the pathways of mitochondrial dysfunction and metabolism were identified. Further studies are needed to clarify the roles of these proteins in myocardial metabolism remodeling during acute MI injury.

\section{Introduction}

Coronary artery-related cardiac ischemia is the most common cause of cardiomyopathy and heart failure, with high rates of morbidity and mortality worldwide (1). Coronary artery stenosis and/or occlusion lead to myocardial perfusion reduction, cardiomyocyte remodeling and fibrosis, dilated ventricles and even heart failure. Exploring the pathogenesis and regulatory mechanisms of ischemia may provide significant benefits in its diagnosis, treatment, and prognosis. Cardiac ischemia is a type of complex cellular and molecular activity that occurs at multiple levels (2-8). However, its mechanisms are yet to be fully elucidated. The heart is an organ rich in mitochondria and thus particularly vulnerable to ischemia. Due to the role of the 'energy power plant', mitochondrial homeostasis is crucial for vital cellular activities.

In the past few decades, omics technology has made a remarkable contribution to illustrating the pathogenesis and consequences of cardiac ischemia. Proteomics is a type of omics approach that focuses on systemic and dynamic molecular changes, and explores potential crosstalk between multiple 
molecular levels and pathways. Expression analysis via liquid chromatography-tandem mass spectrometry (LC-MS/MS) is used to investigate persistent and chronic myocardial ischemia (MI) (9-13). Transient coronary clamps cause severe cardiac ischemia and injury, accompanied by metabolic disturbances (14). Our recent unpublished experiments showed that 15 min of ligation of the left anterior descending (LAD) artery resulted in impaired mitochondrial morphology. Based on these results, it was hypothesized that mitochondrial proteome disturbance may occur in the very early stages of ischemia. In the present study, the mitochondrial proteome profiles of mice hearts that underwent short-term LAD ligation were evaluated using LC-MS/MS proteome expression analysis. More than 1,700 proteins were screened, and 119 differentially expressed proteins were identified. A number of proteins were involved in the activities and pathways that regulate oxidative phosphorylation (OXPHOS), complement activation and mitochondrial autophagy. These results indicated that mitochondrial proteomic changes may serve as potential biomarkers for a very early stage of ischemic cardiac injury and provide novel insights into the mechanism of myocardial remodeling.

\section{Materials and methods}

Animals and grouping. The animals used were 8-week-old male C57BL/6N mice and their body weights were 20-25 g. The animals were purchased from the Beijing Vital River Laboratory Animal Technology Co., Ltd. The mice were housed under a $12 \mathrm{~h}$ light/dark cycle at $22 \pm 2^{\circ} \mathrm{C}$ and at a relative humidity of 40-60\%. They had free access to standard mouse chow and tap water. After one week of adaptive feeding, the 24 mice were randomly divided into an acute MI group and a sham group. All experiments and procedures were approved by the Institutional Animal Care and Use Committee Review Board of the General Hospital of Ningxia Medical University (approval no. 2020-01) and complied with the guidelines of the National Institutes of Health Animal Care and Use Committee.

Acute MI model establishment. The MI mouse model was established by ligation of the LAD, following previously reported methods (15-17). The mice were anesthetized with a $2 \%$ isoflurane (RWD) by a delivery machine (Pat.4879997, VAPOMATIC $^{\text {тм }}$, CWE13-13000) at an airflow rate of $0.8 \mathrm{l} / \mathrm{min}$. Deep sedation was confirmed by the absence of corneal and toe pinch reflexes. After disinfecting the surgical area, a 1-2 cm skin cut was made over the left side of the chest. After dissection and retraction of the pectoral major and minor muscles, the fourth intercostal space was exposed. A small hole was made at the fourth intercostal space with a mosquito clamp to open the pleural membrane and pericardium. Then the heart was smoothly and gently 'popped out' through the hole. The LAD was quickly ligated using a 6-0 silk suture $\sim 1 \mathrm{~mm}$ distal to the left atrial appendage and $2 \mathrm{~mm}$ in width and depth. The ST-segment elevation on the ECG recording (PowerLab System, AD Instruments) was used to confirm successful occlusion of the LAD. The heart was placed back into the intrathoracic space immediately after ligation. The muscles and skin were closed. The operation in the sham group was the same, except no LAD ligation was performed.
After 15 min of ligation, the animals were euthanized under anesthesia of $5 \%$ isoflurane by a delivery machine at an airflow rate of $1.0 \mathrm{l} / \mathrm{min}$, and the left ventricles were collected immediately.

Preparation of samples for transmission electron microscopy (TEM) examination. A small piece $\left(1 \mathrm{~mm}^{3}\right)$ of the fresh left ventricle myocardium was rinsed in ice-cold PBS, and the buffer was then removed using clean filter paper. The tissues were fixed in $2 \%$ glutaraldehyde for $2 \mathrm{~h}$, washed with $0.1 \mathrm{M}$ dimethyl sodium arsenate three times, fixed in $4 \%$ osmic acid for $2 \mathrm{~h}$, rinsed again in $0.1 \mathrm{M}$ dimethyl sodium arsenate and successively dehydrated with 30-50-70\% alcohol solutions. These processes were performed at $4^{\circ} \mathrm{C}$. The fixed tissues were infiltrated with propylene oxide and embedded in epoxy resin at $60^{\circ} \mathrm{C}$ for $48 \mathrm{~h}$. The tissues were then cut into ultrathin sections and observed and imaged by TEM (Hitachi HT-7800; Hitachi, Ltd.; magnifications, x1,500, x5,000 and x10,000) after staining with $2 \%$ uranyl acetate for $15 \mathrm{~min}$ at room temperature and lead citrate for $5 \mathrm{~min}$ at room temperature.

Flameng's classification method was used to quantify mitochondrial injury under TEM as previously reported (18). At the same magnification (x5,000), 5 fields were randomly selected for imaging, and 20 mitochondria were randomly selected from each field for analysis in each mouse. According to the damage degree, the mitochondria were graded on a scale of 0 to 4 as follows: 0 , normal ultrastructure of the mitochondrion; 1 , normal ultrastructure of the crests and matrix but absence of granular deposits; 2 , loss of matrix granules and clarification of the matrix without breaking of crests; 3 , disruption of mitochondrial crests with clarification as well as condensation of the matrix; and 4, disruption of crests, and loss of integrity of the mitochondrial membranes. The final score is presented as the median and was analyzed using a Mann-Whitney U test. The experiment was repeated 3 times.

Mitochondrial isolation. Cardiac mitochondria were extracted using a mitochondrial isolation kit (Nanjing KeyGen Biotech Co., Ltd.; cat. no. KGA827) according to the manufacturer's instructions. The fresh left ventricle was immediately placed on ice, rinsed with cold saline and drained with filter paper. Then, 40-60 mg of tissue was cut into small pieces using ophthalmic scissors and transferred into a small volume $(2 \mathrm{ml})$ glass homogenizer. Next, ice-cold lysis buffer $(1 \mathrm{M}$ Tris- $\mathrm{HCl}$, $25 \mathrm{mM} \mathrm{MgCl}_{2}, 0.5 \mathrm{M} \mathrm{KCl}$ ) was added to the homogenizer until the accumulated volume was 6 -fold that of the tissue pieces. The tissue was ground 20 times at $4^{\circ} \mathrm{C}$. After adding medium buffer ( $2 \mathrm{M}$ sucrose), the homogenate was centrifuged at $1,200 \mathrm{x} \mathrm{g}$ for $5 \mathrm{~min}$ at $4^{\circ} \mathrm{C}$ twice. The supernatant was collected and centrifuged at $7,000 \mathrm{x}$ g for $10 \mathrm{~min}$ at $4^{\circ} \mathrm{C}$. The pellet contained mitochondria. Finally, the purified mitochondria were obtained by centrifugation at 9,500 $\mathrm{x} \mathrm{g}$ for $5 \mathrm{~min}$ at $4^{\circ} \mathrm{C}$ after adding suspension buffer $(1 \mathrm{M}$ Tris- $\mathrm{HCl}, 25 \mathrm{mM}$ $\mathrm{MgCl}_{2}, 2 \mathrm{M}$ sucrose). Part of the freshly purified mitochondria was used for the respiration function study, and the rest was stored at $-80^{\circ} \mathrm{C}$ for proteomic analysis.

Western blotting. The mitochondrial proteins were extracted using a mitochondrial protein isolation kit (Nanjing KeyGen Biotech Co., Ltd.; cat. no. KGP850) according to the 
manufacturer's instructions. All steps were performed in an ice bath. Protein concentration was determined using a bicinchoninic acid (BCA) protein detection kit (Nanjing KeyGen Biotech Co., Ltd.; cat. no. KGPBCA). Proteins (40 $\mu \mathrm{g} / \mathrm{lane})$ were loaded and resolved on $10 \%$ SDS-PAGE and transferred to a nitrocellulose membrane. Mitochondrial transmembrane protein voltage-dependent anion-selective channel protein 1 (VDAC1) antibody (Abcam; cat. no. ab154856; 1:5,000) was used to confirm the efficiency of mitochondrial isolation and rabbit anti-GAPDH (BIOSS; cat. no. bs-2188R; 1:5,000) was used as the loading control. The nitrocellulose membrane was blocked in $10 \%$ skim milk for $1 \mathrm{~h}$ at $22 \pm 2^{\circ} \mathrm{C}$ and then incubated with anti-VDAC1 overnight at $4^{\circ} \mathrm{C}$. The VDAC1 membrane was stripped and reblotted with GAPDH overnight at $4^{\circ} \mathrm{C}$. Horseradish peroxidase-labeled anti-rabbit secondary antibody (Abbkine, Inc.; cat. no. A21020; 1:5,000) was used to detect the primary antibodies.

Measurement of mitochondrial membrane potential (MMP). MMP was analyzed using a fluorescent probe JC-1 assay kit (Beyotime Institute of Biotechnology; cat. no. C2006). JC-1 working solution was added to the purified mitochondria and mixed. The mixture was then added to a 96-well plate. Readings were measured using a fluorescence microplate reader (VICTOR Nivo; PerkinElmer, Inc.) at excitation and emission wavelengths of 485 and $590 \mathrm{~nm}$, respectively.

\section{Mitochondria proteome LC-MS/MS analysis}

Protein digestion. The purified mitochondria were powdered in liquid nitrogen and transferred to a $5 \mathrm{ml}$ centrifuge tube. Four volumes of lysis buffer ( $8 \mathrm{M}$ urea, $1 \%$ protease inhibitor cocktail) were added to the powder and sonicated three times on ice using a high-intensity ultrasonic processor (Scientz). The remaining debris were removed by centrifugation at $12,000 \mathrm{xg}$ for $10 \mathrm{~min}$ at $4^{\circ} \mathrm{C}$. Finally, the supernatant was collected, and the protein concentration was determined using a BCA assay. For digestion, the protein solution was reduced with $5 \mathrm{mM}$ dithiothreitol for $30 \mathrm{~min}$ at $56^{\circ} \mathrm{C}$ and alkylated with $11 \mathrm{mM}$ iodoacetamide for $15 \mathrm{~min}$ at room temperature in the dark. Then, the urea concentration in the protein sample was diluted to $<2 \mathrm{M}$ with $100 \mathrm{mM} \mathrm{NH} \mathrm{HCO}_{3}$. Finally, trypsin was added at a ratio of 1:50 trypsin: protein mass for the first digestion overnight and a ratio of 1:100 trypsin: protein mass for the second $4 \mathrm{~h}$ of digestion.

LC-MS/MS analysis. Tryptic peptides were dissolved in $0.1 \%$ formic acid and then loaded. The high performance liquid chromatography gradient increased from 6 to $23 \%$ ( $0.1 \%$ formic acid in $98 \%$ acetonitrile) over $26 \mathrm{~min}, 23$ to $35 \%$ over $8 \mathrm{~min}$, and increased to $80 \%$ over $3 \mathrm{~min}$, then held at $80 \%$ for $3 \mathrm{~min}$. On the EASY-nLC 1,000 ultra-performance LC (UPLC) system, the constant flow rate was $400 \mathrm{nl} / \mathrm{min}$. The peptides were subjected to a nanojet ionization source followed by MS/MS in the Q Exactive ${ }^{\mathrm{TM}}$ Plus (Thermo Fisher Scientific, Inc.) coupled online to the UPLC. The electrospray voltage applied was $2.0 \mathrm{kV}$. The resolution of the intact peptide detected in Orbitrap was 70,000 Da. Then, the peptides were selected with normalized collision energy setting a value of 28 for MS/MS, and the fragments were detected in the Orbitrap at a resolution of 17,500. Automatic gain control was set at 5E4. For MS scans, the m/z scan range was 350-1,800. Label-free quantification was performed as described in a previous study (19-21).

Database search and bioinformatics analysis. The MS/MS data were processed using the MaxQuant search engine (v.1.5.2.8). The original data were obtained via database retrieval. Unsupervised principal component analysis (PCA) was used to observe the overall distribution of proteins among the samples and the stability of the analytical process. Proteins were classified by Gene Ontology (GO) annotation $(22,23)$ into the three following categories: Cellular component, molecular function, and biological process. The Kyoto Encyclopedia of Genes and Genomes (KEGG) was used to analyze pathway enrichment (24). For each category, a two-tailed Fisher's exact test was used to assess the enrichment of differentially expressed proteins vs. all identified proteins. The GO and KEGG terms with a corrected $\mathrm{P}<0.05$ were considered statistically significant. The - $\log 10(\mathrm{P}$-value) represents enrichment degree. The cluster membership was visualized using a heatmap.

Statistical analysis. All data were analyzed using SPSS v23.0 (IBM Corp) and GraphPad Prism v5.0 (GraphPad Software, Inc.). The results are presented as the mean \pm standard deviation. An unpaired t-test was used to compare the means between the groups. The test significance level was $\alpha=0.05$, and $\mathrm{P}<0.05$ was considered to indicate a statistically significant difference. The differentially expressed proteins were screened by fold change (FC) and an unpaired t-test. The differential screening conditions were $\mathrm{FC}=1.2 \mathrm{x}$ and $\mathrm{P}<0.05$. Both $\mathrm{FC}=0$ and $\mathrm{FC}=\inf$ belong to the difference of 'with or without'. A two-tailed Fisher's exact test was applied to test the protein enrichment analysis, and a corrected P-value $<0.05$ was considered to be significant. These enrichment analyses were performed according to the database of identified proteins and a two-tailed Fisher's exact test was employed. All terms with corrected a P-value $<0.05$ were considered significantly enriched differentially expressed proteins. The number of experimental replications was 3 .

\section{Results}

Acute MI induced mitochondrial morphological changes. First, TEM was used to examine the myocardium and mitochondrial morphology following MI. As shown in Fig. 1A and C, the sarcomeres were intact, the muscle filaments were neatly arranged, the nuclear membrane was intact (Fig. S1), and the chromatin was uniformly arranged. Mitochondria were normal and ridges were visible and not dissolved or ruptured in the sham group. The outer membrane dissolution and break down of the inner membrane (cristae) in some mitochondria was observable in the MI group (Fig. 1B and D; red arrows). The mitochondrial score in the MI group increased significantly $(\mathrm{P}<0.05)$ compared with the sham group (Fig. 1E). These results indicated that acute MI induced mitochondrial damage.

Acute MI decreases MMP. Fig. 2A shows that VDAC1 protein expression was strong (the original uncropped western blots shown in Fig. S2) and the mitochondria were efficiently isolated in both groups (Fig. 2B).The MMP was evaluated using a JC-1 

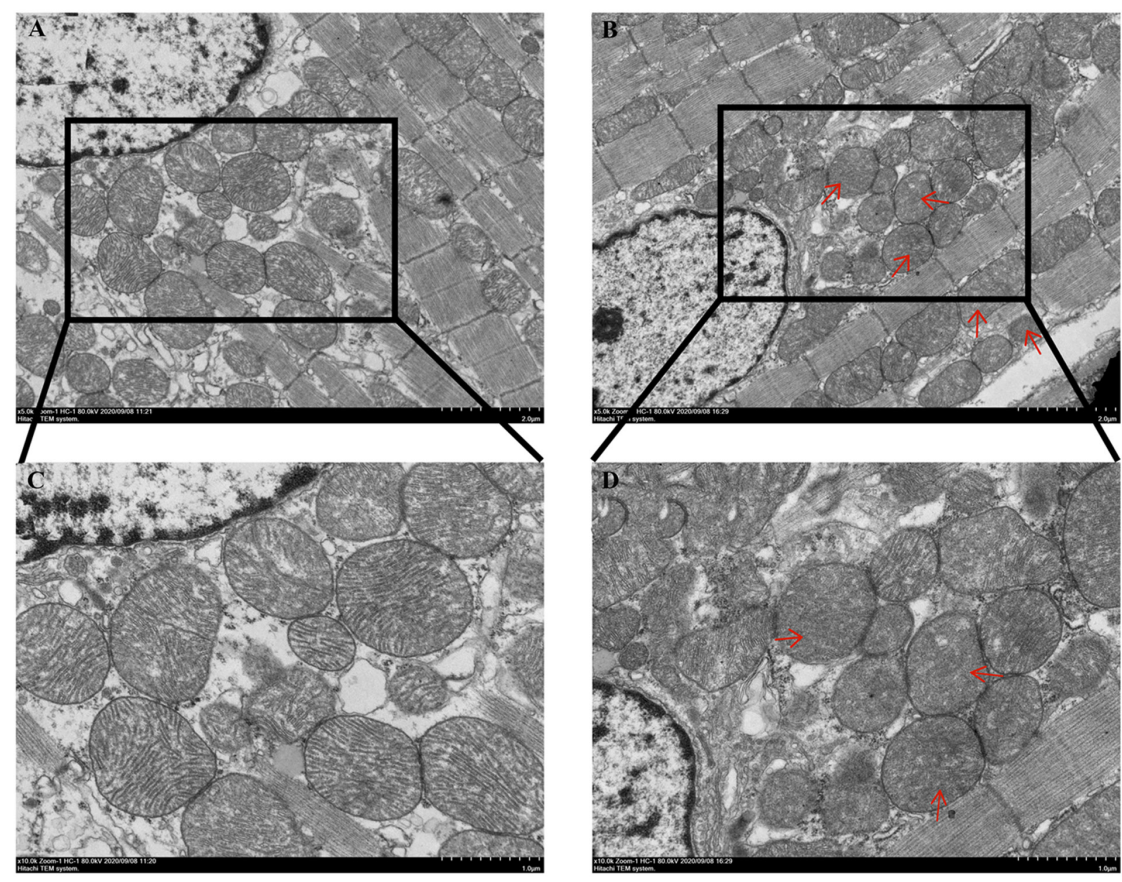

E

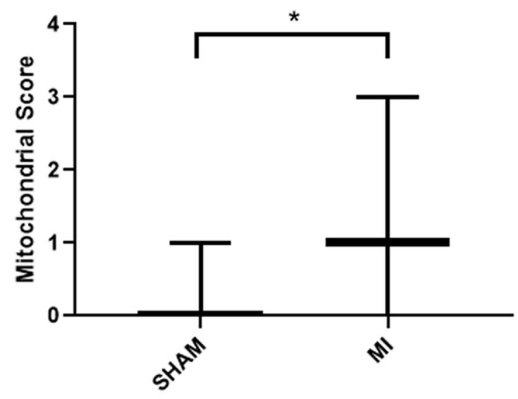

Figure 1. Mitochondrial morphology observed using transmission electron microscopy. Mitochondrial morphology in the (A) Sham and (B) MI group. Scale bar, $2 \mu \mathrm{m}$. Mitochondrial morphology insets of the (C) Sham and (D) MI group images in (A) and (B). Scale bar, $1 \mu \mathrm{m}$. (E) Mitochondrial score. "P<0.05. $\mathrm{n}=3$ per group. MI, myocardial ischemia.

assay. The results showed that the MMP of the MI group was lower than that of the sham group (Fig. $2 \mathrm{C}, \mathrm{P}<0.05$ ).

Mitochondrial proteomics. First, the expression of trusted proteins was analyzed using PCA (Fig. 3). The results showed substantial differences between the two groups. More than 1,700 trusted proteins were identified in this study. Through the analysis and synchronous comparison of myocardial mitochondria in three separated samples of the sham and MI groups, 119 differential proteins were confirmed. Overall, 27 of the 119 proteins were upregulated and 16 were downregulated compared with the sham group (Table I), and the remaining 76 proteins showed 'yes' or 'no' differences between the two groups (Tables II and III). These results identified LAD ligation/ischemia as the principal source of variance. The volcano map shows the overall distribution of the proteins (Fig. 4). The differentially expressed proteins were screened using $\mathrm{FC}=1.2$ and $\mathrm{P}<0.05$ as the screening conditions. The blue and red dots represent the significantly downregulated and upregulated proteins, respectively. The gray dots represent non-significant proteins. Unsupervised hierarchical clustering was used to group differentially expressed proteins according to their expression profiles. The results are shown in a heatmap (Fig. S3). Each line in the heatmap represents a protein with mean upregulation (red) or downregulation (purple) in expression within the two groups. The proteins that did not exhibit significant differences in expression are indicated in white. NADH dehydrogenase (ubiquinone) iron-sulfur protein 6(NDUFS6), cytochrome b-c1 complex subunit 1 (UQCRC1), thrombospondin-1 (THBS1) and pyruvate dehydrogenase phosphatase regulatory subunit (PDPR) were upregulated, and dynactin subunit 2 (DCTN2) and a-kinase anchor protein 1 (AKAP1) were downregulated in the ischemic group. Cytochrome $\mathrm{C}$ oxidase (COX) assembly protein COX11, mitochondrion adenosine triphosphate (ATP) synthase $\mathrm{F}(0)$ complex subunit $\mathrm{C} 2$ (ATP5G2), mitochondria ubiquitin ligase activator of NF-kB1 (MUL1) were identified in the MI group and E3 ubiquitin-protein ligase UBR3 was identified in the sham group.

According to the GO database, the enrichment of the total, upregulated, and downregulated differentially expressed proteins were analyzed (Fig. 5A-C). For each category, a two-tailed Fisher's exact test was used to test the enrichment of differentially expressed proteins vs. all identified proteins. The GO term with a corrected P-value $<0.05$ was considered statistically significant. Proteins were classified by 
Table I. Downregulated and upregulated proteins in the MI group.

\begin{tabular}{|c|c|c|c|c|c|}
\hline Accession no. & Gene & Protein description & $\mathrm{FC}$ & P-value & Type \\
\hline Q99KJ8 & DCTN2 & Dynactin subunit 2 & 0.315 & $0.001^{\mathrm{c}}$ & Down \\
\hline P31725 & S100A9 & Protein S100-A9 & 0.323 & $0.015^{\mathrm{a}}$ & Down \\
\hline Q3UH59 & MYH10 & Myosin-10 & 0.370 & $0.020^{\mathrm{a}}$ & Down \\
\hline Q62448 & EIF4G2 & Eukaryotic translation initiation factor $4 \gamma 2$ & 0.423 & $0.026^{\mathrm{a}}$ & Down \\
\hline Q8VCQ8 & CALD1 & Caldesmon 1 & 0.492 & $0.028^{\mathrm{a}}$ & Down \\
\hline P19157 & GSTP1 & Glutathione S-transferase P1 & 0.542 & $0.010^{\mathrm{b}}$ & Down \\
\hline O08715 & AKAP1 & A-kinase anchor protein 1 , mitochondrial & 0.593 & $0.048^{\mathrm{a}}$ & Down \\
\hline A0A0A6YX73 & PRKAR2 $\alpha$ & $\begin{array}{l}\text { cAMP-dependent protein kinase type II- } \alpha \\
\text { regulatory subunit }\end{array}$ & 0.619 & $0.036^{\mathrm{a}}$ & Down \\
\hline Q9CQS4 & SLC25A46 & Solute carrier family 25 member 46 & 0.620 & $0.035^{\mathrm{a}}$ & Down \\
\hline Q8R2P8 & KARS & Lysine-tRNA ligase & 0.635 & $0.013^{\mathrm{a}}$ & Down \\
\hline P05132 & PRKAC $\alpha$ & cAMP-dependent protein kinase catalytic subunit $\alpha$ & 0.652 & $0.047^{\mathrm{a}}$ & Down \\
\hline P49312 & HNRNPA1 & Heterogeneous nuclear ribonucleoprotein A1 & 0.665 & $0.050^{\mathrm{a}}$ & Down \\
\hline P55096 & ABCD3 & ATP-binding cassette sub-family D member 3 & 0.666 & $<0.001^{\mathrm{c}}$ & Down \\
\hline P14733 & LMNB1 & Lamin-B1 & 0.684 & $0.029^{\mathrm{a}}$ & Down \\
\hline Q9ET78 & JPH2 & Junctophilin-2 & 0.745 & $0.035^{\mathrm{a}}$ & Down \\
\hline Q6ZWN5 & RPS9 & 40S ribosomal protein $\mathrm{S} 9$ & 0.823 & $0.044^{\mathrm{a}}$ & Down \\
\hline Q9D1G1 & RAB1B & Ras-related protein Rab-1B & 1.201 & $0.031^{\mathrm{a}}$ & Up \\
\hline Q9CZ13 & UQCRC1 & Cytochrome b-c1 complex subunit 1 , mitochondrial & 1.479 & $0.048^{\mathrm{a}}$ & Up \\
\hline Q99MR8 & MCCC1 & $\begin{array}{l}\text { Methylcrotonoyl-CoA carboxylase subunit } \alpha \\
\text { mitochondrial }\end{array}$ & 1.496 & $0.043^{\mathrm{a}}$ & Up \\
\hline Q8R5L1 & C1QBP & $\begin{array}{l}\text { Complement component } 1 \mathrm{Q} \text { subcomponent-binding } \\
\text { protein, mitochondrial }\end{array}$ & 1.591 & $0.027 \mathrm{a}$ & Up \\
\hline Q3ULD5 & MCCC2 & $\begin{array}{l}\text { Methylcrotonoyl-CoA carboxylase } \beta \text { chain, } \\
\text { mitochondrial }\end{array}$ & 1.612 & $0.013^{\mathrm{a}}$ & Up \\
\hline Q9ER35 & FN3K & Fructosamine-3-kinase & 1.654 & $0.013^{\mathrm{a}}$ & Up \\
\hline P84096 & RHOG & Rho-related GTP-binding protein RhoG & 1.676 & $0.031^{\mathrm{a}}$ & Up \\
\hline Q7TSQ8 & PDPR & $\begin{array}{l}\text { Pyruvate dehydrogenase phosphatase regulatory } \\
\text { subunit, mitochondrial }\end{array}$ & 1.724 & $0.046^{\mathrm{a}}$ & Up \\
\hline Q921I1 & $\mathrm{TF}$ & Serotransferrin & 1.731 & $0.025^{\mathrm{a}}$ & Up \\
\hline Q5FWK3 & ARHGAP1 & Rho GTPase-activating protein 1 & 1.800 & $0.017^{\mathrm{a}}$ & Up \\
\hline A0A0R4J0I1 & SERPINA3K & Serine protease inhibitor $\mathrm{A} 3 \mathrm{~K}$ & 1.810 & $0.005^{\mathrm{b}}$ & Up \\
\hline Q00897 & SERPINA1D & $\alpha-1$-antitrypsin $1-4$ & 1.820 & $0.026^{\mathrm{a}}$ & Up \\
\hline Q8BJ03 & COX15 & $\begin{array}{l}\text { Cytochrome c oxidase assembly protein } \\
\text { COX } 15 \text { homolog }\end{array}$ & 1.878 & $0.017^{\mathrm{a}}$ & Up \\
\hline O08528 & HK2 & Hexokinase-2 & 1.912 & $0.015^{\mathrm{a}}$ & Up \\
\hline P48036 & ANXA5 & Annexin A5 & 1.951 & $0.049^{\mathrm{a}}$ & Up \\
\hline Q60994 & ADIPOQ & Adiponectin & 1.951 & $0.031^{\mathrm{a}}$ & Up \\
\hline P07724 & ALB & Serum albumin & 1.969 & $0.031^{\mathrm{a}}$ & Up \\
\hline P52503 & NDUFS6 & $\begin{array}{l}\text { NADH dehydrogenase [ubiquinone] } \\
\text { iron-sulfur protein } 6 \text {, mitochondrial }\end{array}$ & 2.175 & $0.046^{\mathrm{a}}$ & Up \\
\hline A0A0R4J0X5 & SERPINA1C & Alpha-1-antitrypsin 1-3 & 2.536 & $0.045^{\mathrm{a}}$ & Up \\
\hline Q61838 & $\mathrm{A} 2 \mathrm{M}$ & Alpha-2-macroglobulin & 2.764 & $0.019^{\mathrm{a}}$ & Up \\
\hline O35639 & ANXA3 & Annexin A3 & 2.867 & $0.002^{\mathrm{b}}$ & Up \\
\hline Q91VB8 & HBA-A1 & Alpha globin 1 & 3.001 & $0.037^{\mathrm{a}}$ & Up \\
\hline P05064 & ALDOA & Fructose-bisphosphate aldolase A & 3.409 & $0.026^{\mathrm{a}}$ & Up \\
\hline A8DUK4 & HBB-BS & $\beta$-globin & 3.730 & $0.004^{\mathrm{b}}$ & Up \\
\hline E9QNT8 & ANK1 & Ankyrin-1 & 3.885 & $0.040^{\mathrm{a}}$ & Up \\
\hline P01027 & C3 & Complement C3 & 4.137 & $0.044^{\mathrm{a}}$ & Up \\
\hline Q80YQ1 & THBS1 & Thrombospondin-1 & 5.096 & $0.036^{\mathrm{a}}$ & Up \\
\hline
\end{tabular}

${ }^{\mathrm{a}} \mathrm{P} \leq 0.05,{ }^{\mathrm{b}} \mathrm{P} \leq 0.01,{ }^{\mathrm{C}} \mathrm{P} \leq 0.001$. Up, upregulated; Down, downregulated. 
Table II. Proteins specific to the SHAM group.

\begin{tabular}{|c|c|c|c|}
\hline Accession no. & Gene & Protein descriptions & Type \\
\hline Q8K0M3 & SORBS3 & Vinexin & Up \\
\hline A2A848 & ACOX1 & Peroxisomal acyl-coenzyme A oxidase 1 & Up \\
\hline A8Y5P4 & MAP7D1 & MAP7 domain-containing protein 1 & Up \\
\hline A2AS45 & PKP4 & Plakophilin-4 & Up \\
\hline A4QPC5 & CMA1 & Chymase & $\mathrm{Up}$ \\
\hline D3YYT1 & GLYR1 & Putative oxidoreductase GLYR1 & Up \\
\hline D3Z598 & LTBP4 & Latent-transforming growth factor beta-binding protein 4 & Up \\
\hline E9Q6Q8 & TBC1D4 & TBC1 domain family member 4 & Up \\
\hline Q5U430 & UBR3 & E3 ubiquitin-protein ligase UBR3 & Up \\
\hline F7A1B4 & ENG & Endoglin & Up \\
\hline O54774 & AP3D1 & AP-3 complex subunit delta-1 & $\mathrm{Up}$ \\
\hline O55022 & PGRMC1 & Membrane-associated progesterone receptor component 1 & Up \\
\hline O88587 & COMT & Catechol O-methyltransferase & Up \\
\hline P13541 & MYH3 & Myosin-3 & $\mathrm{Up}$ \\
\hline P63163 & SNRPN & Small nuclear ribonucleoprotein-associated protein $\mathrm{N}$ & Up \\
\hline P37804 & TAGLN & Transgelin & Up \\
\hline Q8BVQ9 & PSMC2 & $26 \mathrm{~S}$ protease regulatory subunit 7 & $\mathrm{Up}$ \\
\hline Q3U962 & COL5A2 & Collagen alpha-2(V) chain & $\mathrm{Up}$ \\
\hline Q921L6 & CTTN & Src substrate cortactin & Up \\
\hline Q60972 & RBBP4 & Histone-binding protein RBBP4 & $\mathrm{Up}$ \\
\hline Q6P549 & INPPL1 & Phosphatidylinositol 3,4,5-trisphosphate 5-phosphatase 2 & Up \\
\hline Q6ZWQ9 & MYL12A & Myosin, light chain 12A, regulatory, non-sarcomeric & Up \\
\hline Q8BGU5 & CCNY & Cyclin-Y & Up \\
\hline Q8VCI5 & PEX19 & Peroxisomal biogenesis factor 19 & $\mathrm{Up}$ \\
\hline Q99N92 & MRPL27 & $39 \mathrm{~S}$ ribosomal protein $\mathrm{L} 27$, mitochondrial & Up \\
\hline Q9D666 & SUN1 & SUN domain-containing protein 1 & Up \\
\hline Q9DAW9 & CNN3 & Calponin-3 & $\mathrm{Up}$ \\
\hline Q9JIK5 & DDX21 & Nucleolar RNA helicase 2 & Up \\
\hline Q9JKY7 & CYP2D22 & Cytochrome P450 CYP2D22 & Up \\
\hline Q9JLB0 & MPP6 & MAGUK p55 subfamily member 6 & $\mathrm{Up}$ \\
\hline Q9JLH8 & TMOD4 & Tropomodulin-4 & $\mathrm{Up}$ \\
\hline Q9JMG7 & HDGFRP3 & Hepatoma-derived growth factor-related protein 3 & Up \\
\hline Q9Z0P5 & TWF2 & Twinfilin-2 & $\mathrm{Up}$ \\
\hline Q9Z2X1 & HNRNPF & Heterogeneous nuclear ribonucleoprotein $\mathrm{F}$ & Up \\
\hline
\end{tabular}

Up, upregulated; Down, downregulated.

GO annotation into the following three categories: Biological processes, cellular components and molecular functions. Pathway enrichment of the top $30 \mathrm{GO}$ terms of the total differentially expressed proteins is shown in Fig. 5A. The most perturbed biological processes were endopeptidase activity regulation and blood coagulation. The mitochondria, protein-containing complex, collagen-containing extracellular matrix and mitochondria inner membrane were the most relevant cellular components. Endopeptidase inhibitor activity and microtubule binding were the most relevant molecular functions.

For the upregulated proteins, the most relevant biological processes were the negative regulation of endopeptidase activity,blood coagulation, theactivation of cysteine-typeendopeptidase activity and the positive regulation of angiogenesis.
The most relevant cellular components included the endoplasmic reticulum, collagen-containing extracellular matrix and extracellular region. The top four molecular functions were identical protein binding, endopeptidase inhibitor activity, protease binding and oxidoreductase activity (Fig. 5B).

For the downregulated proteins, the closely related biological processes included peroxisome organization, negative regulation of MAP kinase activity and positive regulation of axon extension. Except for mitochondria, the most highly relevant cellular components were myofibrils, the mitochondrial outer membrane, the ribonucleoprotein complex and the cytoskeleton. Closely related molecular functions included protein kinase binding, RNA binding, actin filament binding and microtubule-binding (Fig. 5C). 
A
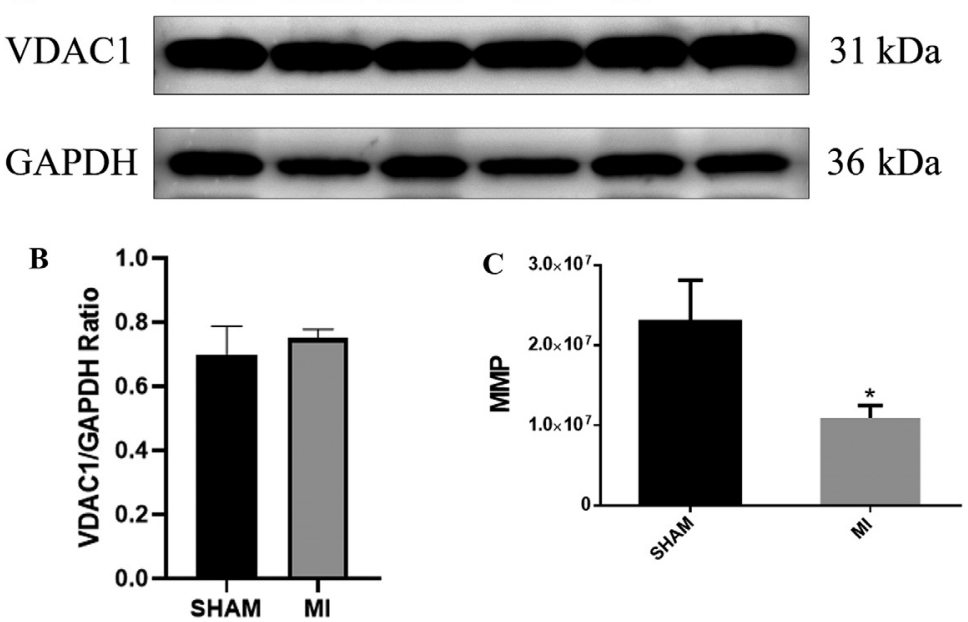

Figure 2. (A) Detection of mitochondrial voltage-dependent anion-selective channel protein 1 (uncropped blots are presented in Fig. S1). (B) The total number of mitochondria did not differ significantly between the sham and MI groups. (C) MMP in the sham and MI groups. "P<0.05. $\mathrm{n}=6$ per group. MI, myocardial ischemia; VDAC1, voltage-dependent anion-selective channel protein 1; MMP, mitochondrial membrane potential.

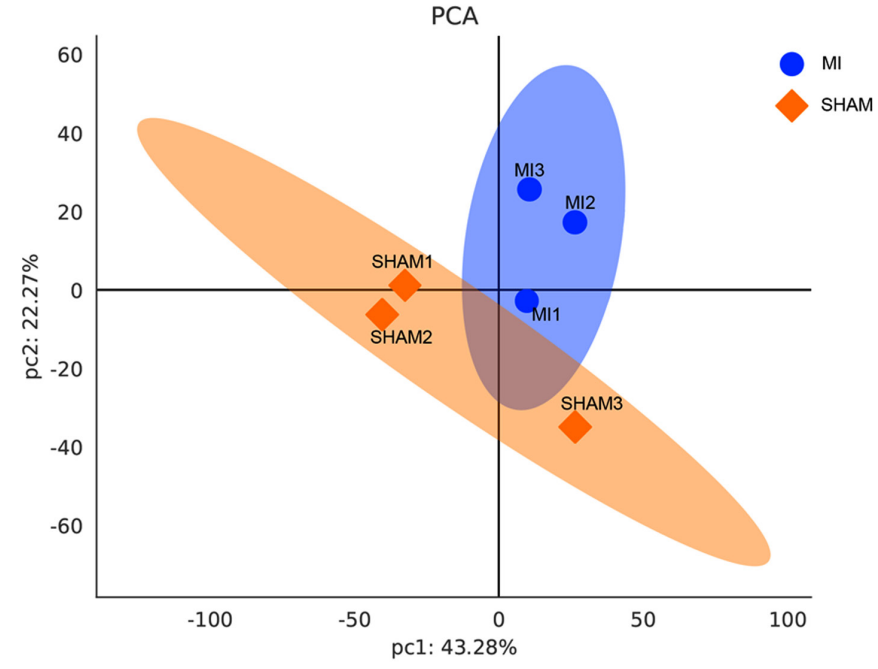

Figure 3. PCA. Each square/spot represents a repetition in a grouping experiment, and different colors represent the different groups. $n=3$ per group. PCA, principal component analysis.

The relationship between the enriched GO terms and the differentially expressed proteins is displayed as a chord diagram in Fig. 6. A small arc on the left side of the chord diagram represents one protein. The color represents the difference: Blue indicates downregulation and red indicates upregulation. The GO terms are shown on the right-hand side of the diagram. Different colors represent different GO terms; that is, different functions. GO terms correspond to multiple differentially expressed proteins, and a protein can participate in multiple GO terms; the mitochondria and collagen-containing extracellular matrices possessed the most enriched proteins.

The KEGG database was used to analyze the metabolic pathways of the proteins. Biological functions related to these proteins were obtained from KEGG enrichment analysis (Fig. 7). The pathways with the most relevant differentially expressed proteins included Parkinson's disease, prion diseases, platelet activation, complement and coagulation

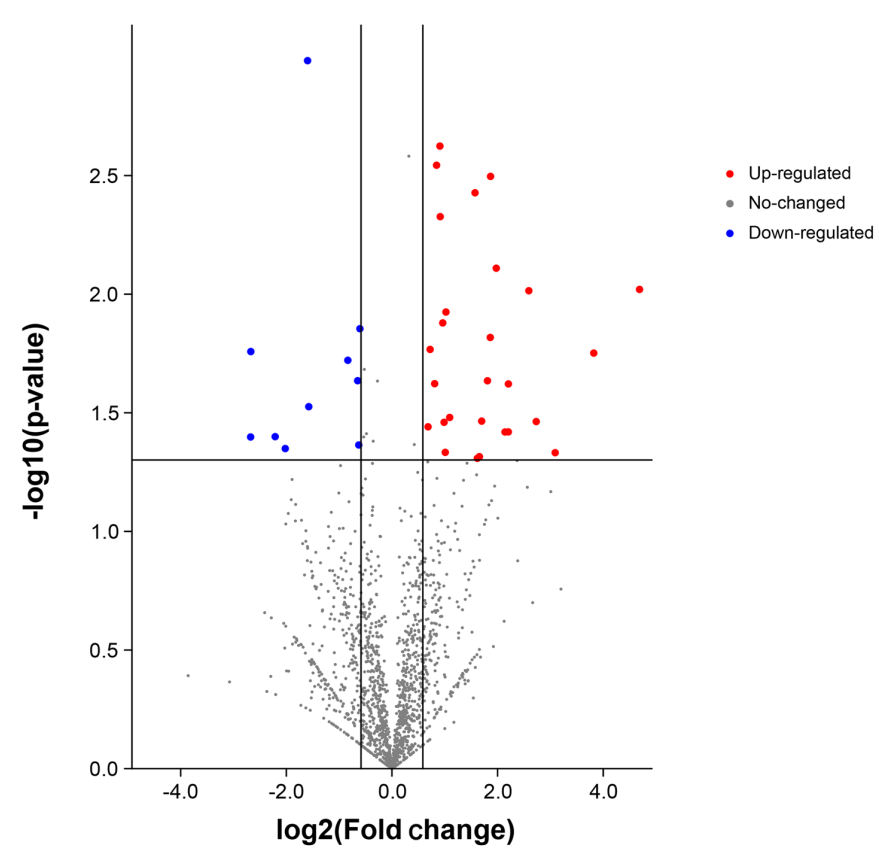

Figure 4. Volcano plot showing the differentially expressed proteins. The abscissa of the volcano plot is $\log 2$ (FC), and the further the value from zero, the higher the difference, with upregulation on the right and downregulation on the left. The ordinate is $-\log 10$ (P-value), and the further the ordinate from zero, the higher the difference. FC, fold change.

cascades, peroxisome, hypoxia-inducible factor-1 (HIF-1) signaling, type 2 diabetes mellitus, fructose and mannose metabolism (Fig. 7A). For upregulated proteins, the most relevant biological functions included Parkinson's disease, non-alcoholic fatty liver disease, focal adhesion, complement, coagulation cascades, the peroxisome proliferator-activated receptor (PPAR) signaling pathway, OXPHOS, the pentose phosphate pathway and the HIF-1 signaling pathway (Fig. 7B). The closely related biological functions of downregulated proteins included vasopressin-regulated water reabsorption, the insulin signaling pathway, dopaminergic synapses, ribosomes, and peroxisomes (Fig. 7C). 

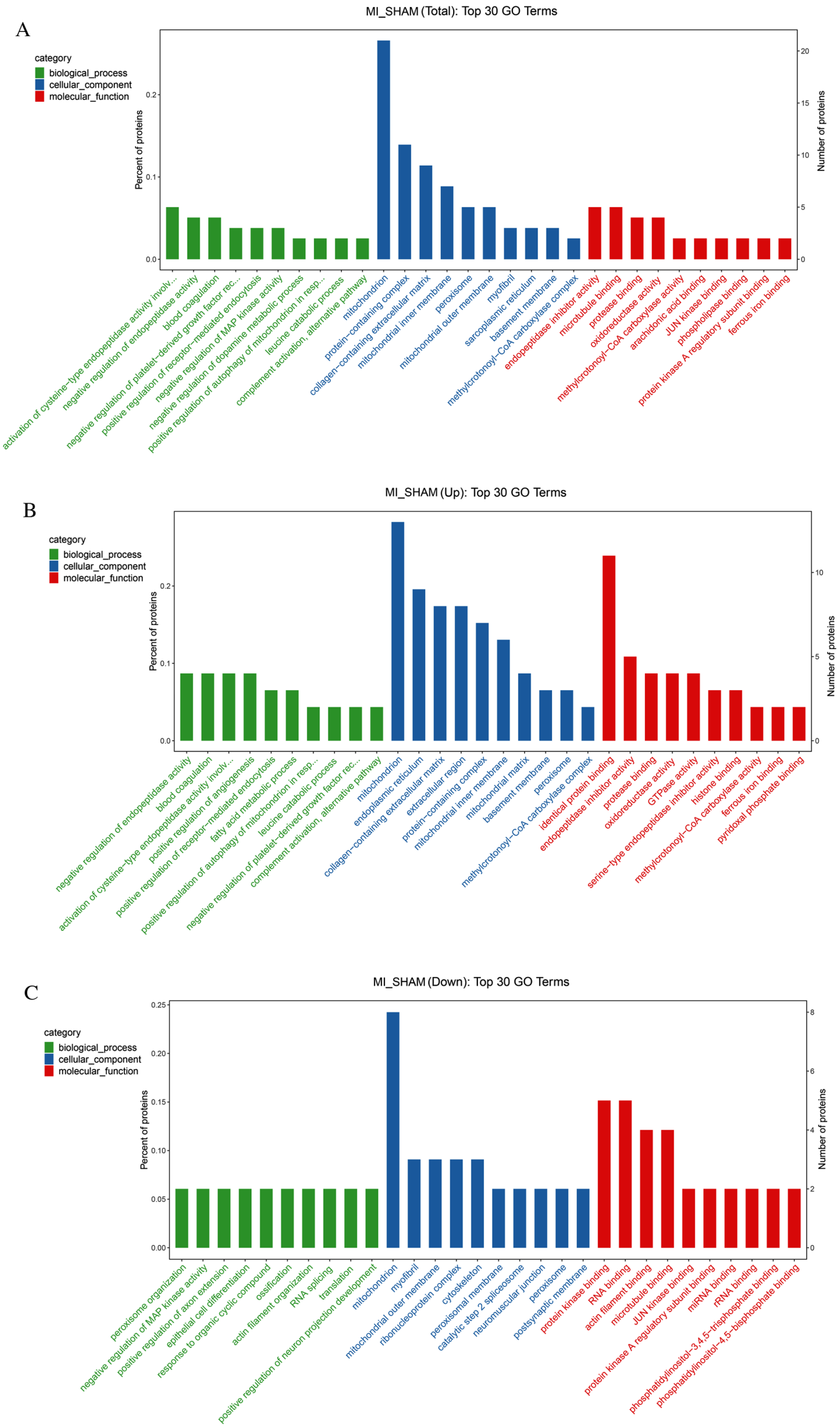

Figure 5. GO enrichment analysis. GO entries screened among (A) all differentially expressed proteins, (B) the upregulated proteins and (C) the downregulated proteins. GO, Gene Ontology; MI, myocardial ischemia. 
Table III. Proteins specific to the MI group.

\begin{tabular}{|c|c|c|c|}
\hline Accession no. & Gene & Protein descriptions & Type \\
\hline A0A075B6A0 & IGHM & Ig mu chain $\mathrm{C}$ region & Up \\
\hline A0A087WQS5 & ATP5G2 & ATP synthase $\mathrm{F}(0)$ complex subunit $\mathrm{C} 2$, mitochondrial & Up \\
\hline E9QP56 & APOC3 & Apolipoprotein C-III & Up \\
\hline F8VPK5 & ROCK2 & Rho-associated protein kinase; Rho-associated protein kinase 2 & Up \\
\hline A0A2I3BPW0 & NDRG2 & $\mathrm{N}$-myc downstream-regulated gene 2 protein & Up \\
\hline A0A3B2WBH9 & TJP2 & Tight junction protein $\mathrm{ZO}-2$ & Up \\
\hline A0A494BB95 & EIF1AX & Eukaryotic translation initiation factor $1 \mathrm{~A}$ & Up \\
\hline $\mathrm{A} 2 \mathrm{AEX} 8$ & FHL1 & Four and a half LIM domains protein 1 & Up \\
\hline B7ZCL8 & MPP1 & $55 \mathrm{kDa}$ erythrocyte membrane protein & Up \\
\hline B8JJM5 & CFB & Complement factor B & Up \\
\hline D6RGQ0 & $\mathrm{CFH}$ & Complement factor $\mathrm{H}$ & Up \\
\hline O88986 & GCAT & 2-amino-3-ketobutyrate coenzyme A ligase, mitochondrial & Up \\
\hline F7AAP4 & ATP2B4 & Calcium-transporting ATPase & Up \\
\hline Q91YX5 & LPGAT1 & Acyl-CoA: lysophosphatidylglycerol acyltransferase 1 & Up \\
\hline Q8CIZ8 & VWF & von Willebrand factor; von Willebrand antigen 2 & Up \\
\hline O55042 & SNCA & Alpha-synuclein & Up \\
\hline O70194 & EIF3D & Eukaryotic translation initiation factor 3 subunit D & Up \\
\hline P01837 & IGKC & Igк chain $\mathrm{C}$ region & Up \\
\hline P06684 & C5 & Complement C5 & Up \\
\hline P07759 & SERPINA3K & Serine protease inhibitor $\mathrm{A} 3 \mathrm{~K}$ & Up \\
\hline P19221 & $\mathrm{F} 2$ & Prothrombin & Up \\
\hline P29699 & AHSG & Alpha-2-HS-glycoprotein & $\mathrm{Up}$ \\
\hline P29788 & VTN & Vitronectin & Up \\
\hline P35550 & FBL & rRNA 2-O-methyltransferase fibrillarin & Up \\
\hline P40142 & TKT & Transketolase & Up \\
\hline P43883 & PLIN2 & Perilipin-2 & Up \\
\hline P49722 & PSMA2 & Proteasome subunit alpha type- 2 & Up \\
\hline Q8CE80 & CAST & Calpastatin & Up \\
\hline P61514 & RPL37A & $60 \mathrm{~S}$ ribosomal protein $\mathrm{L} 37 \mathrm{a}$ & Up \\
\hline P62835 & RAP1A & Ras-related protein Rap-1A & Up \\
\hline Q00519 & $\mathrm{XDH}$ & Xanthine dehydrogenase/oxidase & Up \\
\hline Q5SRC5 & COX11 & Cytochrome c oxidase assembly protein $\mathrm{COX} 11$, mitochondrial & Up \\
\hline Q61578 & FDXR & NADPH: adrenodoxin oxidoreductase, mitochondrial & Up \\
\hline Q6PA06 & ATL2 & Atlastin-2 & Up \\
\hline Q6PDI5 & ECM29;AI314180 & Proteasome-associated protein ECM29 homolog & Up \\
\hline Q8VE37 & $\mathrm{RCC1}$ & Regulator of chromosome condensation & Up \\
\hline Q7TNL9 & CHCHD10 & Coiled-coil-helix-coiled-coil-helix domain-containing 10 & Up \\
\hline Q8BXZ1 & TMX3 & Protein disulfide-isomerase TMX3 & Up \\
\hline Q8VCM5 & MUL1 & Mitochondrial ubiquitin ligase activator of NF- $\kappa \mathrm{B} 1$ & Up \\
\hline Q91X72 & HPX & Hemopexin & Up \\
\hline Q99LB4 & CAPG & Macrophage-capping protein & Up \\
\hline Q9EST5 & ANP32B & Acidic leucine-rich nuclear phosphoprotein 32 family member B & Up \\
\hline
\end{tabular}

Up, upregulated; Down, downregulated.

\section{Discussion}

Ischemic heart disease is the leading cause of heart failure worldwide (1). Disturbances to ATP synthesis resulting from MI leads to energy starvation in the myocardium, resulting in the remodeling of myocardial energy metabolism (25). The heart is one of the most metabolically active organs in the body (26). In the resting state, the human heart uses $6 \mathrm{~kg}$ of ATP per day (27). Cardiac function declines when mitochondrial OXPHOS and ATP production fail to keep up with the demand for energy consumption. Mitochondrial disorders are a sign of cardiovascular disease and heart failure (27). Early 


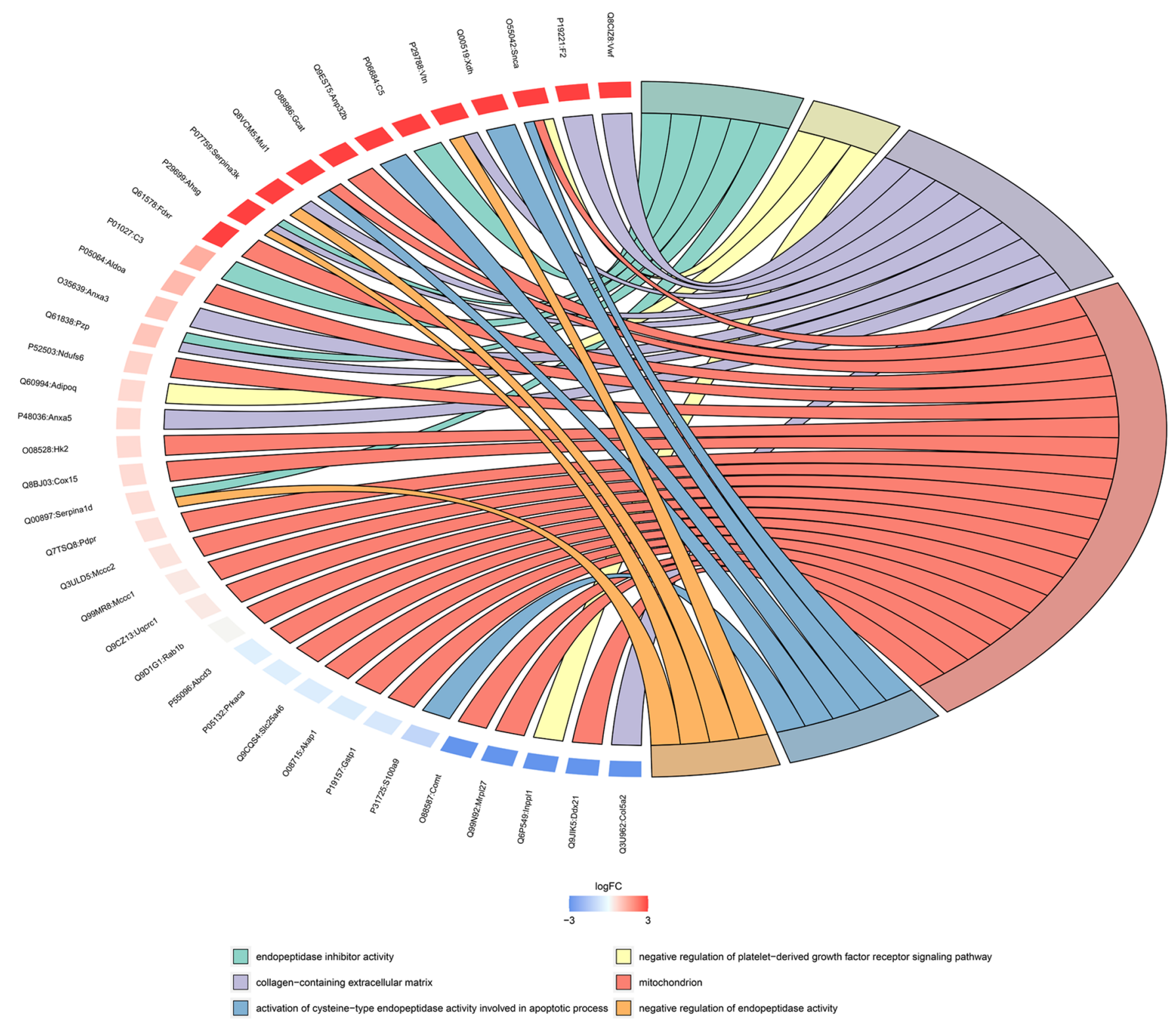

Figure 6. Chord diagram of GO enrichment analysis. The protein names are on the left and the selected GO terms are on the right. Red indicates upregulated and blue indicates downregulated proteins. GO, Gene Ontology.

ultrastructural changes include the depletion of cytoplasmic glycogen particles, and the swelling of cardiomyocyte mitochondria can be observed after a few minutes of ischemia, although these changes are reversible if ischemia lasts no longer than 15-20 min (28). Any change in mitochondrial structure is associated with impaired mitochondrial function, such as the alteration of metabolic substrate utilization, impaired activity of the mitochondrial electron transport chain, increased formation of reactive oxygen species (ROS), and altered ion homeostasis (26). Consequently, cardiac function is affected by these adverse effects (29). Proteins are the ultimate 'executors' of cellular activity and function. To the best of our knowledge, the proteomic characteristics of cardiac mitochondria that suffer from short-term acute ischemia have not previously been reported.

In the present study, cardiac mitochondrial injury, such as outer membrane dissolution, inner membrane (cristae) loss and rupture were observed in the MI group 15 min after LAD ligation. However, the cardiomyocyte membrane, sarcomeres and nuclei remained intact. Decreased MMP measurements also showed damaged mitochondria in the MI group. These results indicated that mitochondria are extremely sensitive to ischemia and may be a potential marker of ischemia onset. Moreover, the results suggested that proteome disturbances are inevitable during this period. To elucidate the proteome changes, the proteome expression profile of the left ventricle mitochondria was evaluated using LC-MS/MS analysis. More than 1,700 proteins were screened, and 119 differentially expressed proteins were confirmed, with 27 upregulated and 16 downregulated proteins in the MI group. In addition, 34 proteins were present in the sham group and 42 in the MI group. Once the differential proteins were identified, GO annotation and the KEGG pathway enrichment analyses were performed to elucidate the proteins' function. According to the GO annotation, the pathway categories include cellular component, molecular function and biological process. 
A

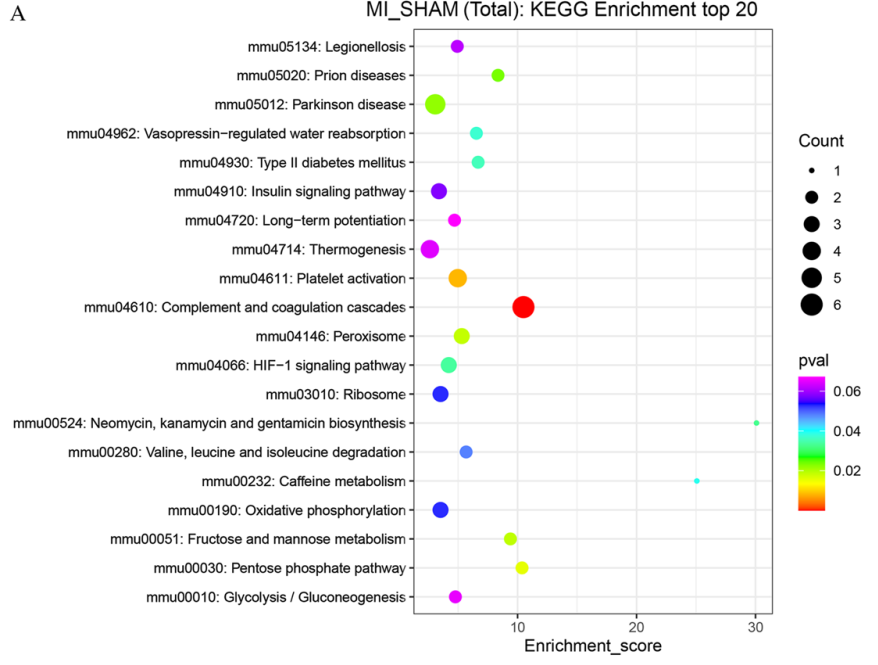

B

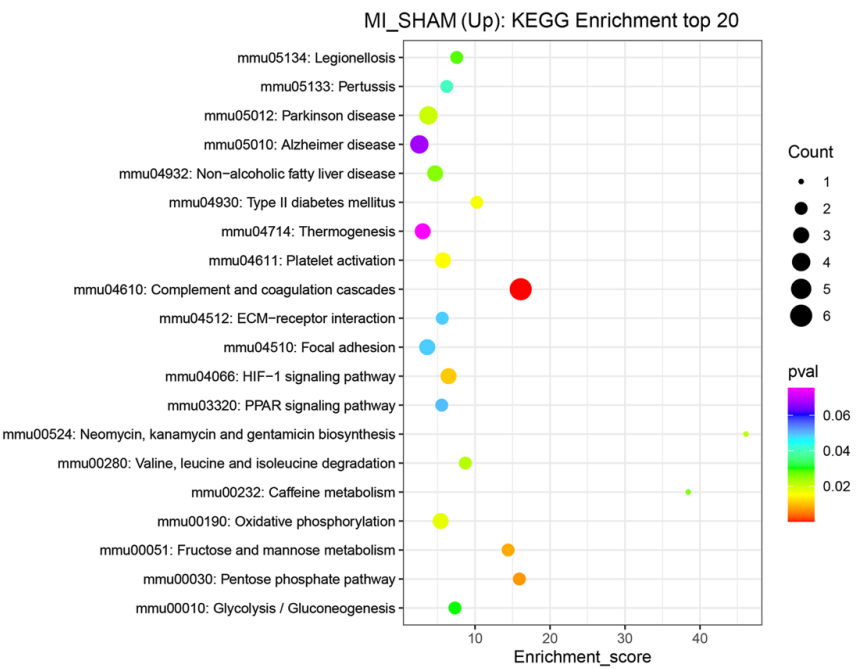

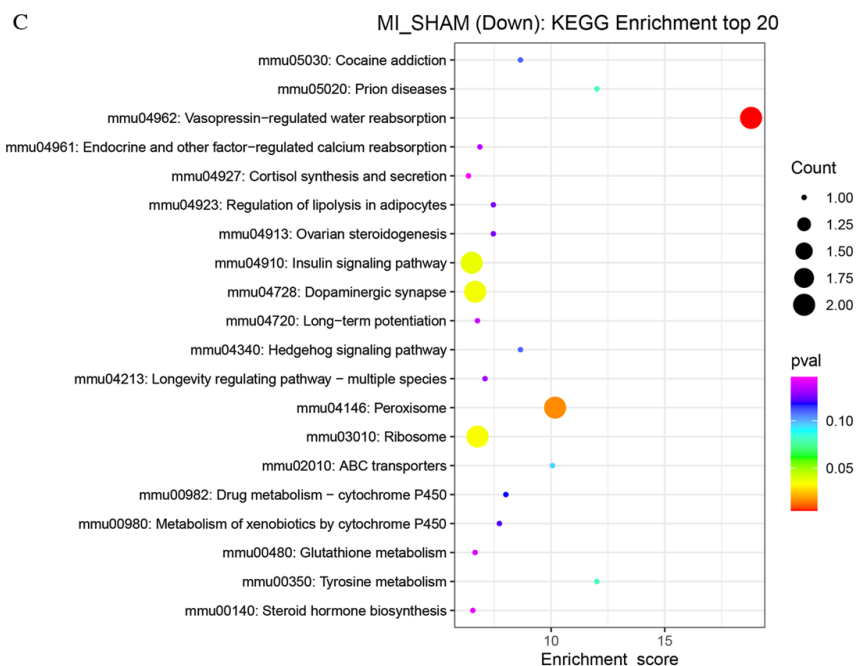

Figure 7. Bubble chart of the KEGG enrichment analysis. The $\mathrm{x}$-axis is the enrichment score and the $y$-axis is the pathway information. The size of the bubbles reflects the number of differentially expressed proteins. The larger the bubble, the higher the number of differentially expressed proteins. The lower the P-value, the higher the significance of the KEGG pathway enrichment. (A) Enrichment metabolic pathways screened among all differentially expressed proteins. (B) Enriched metabolic pathways screened among upregulated proteins. (C) Enriched metabolic pathways screened among downregulated proteins. MI, myocardial ischemia; KEGG, Kyoto Encyclopedia of Genes and Genomes.

Several differentially expressed proteins were involved in the activities and pathways of OXPHOS, complement activation, positive regulation of mitochondrial autophagy, and oxidative dismutase activity. These proteins included numerous upregulated proteins with $\mathrm{FC} \geq 1.47$, such as UQCRC1, pyruvate dehydrogenase phosphatase regulatory subunit, rho GTPase-activating protein 1, NDUFS6, Annexin A3 and A5, complement 1Q subcomponent-binding and protein complement C3, fructose-bisphosphate aldolase A and ankyrin-1, and the downregulated dynactin subunit 2 , myosin 10 , A-kinase anchor protein 1, cAMP-dependent protein kinase type II- $\alpha$ regulatory subunit and cAMP-dependent protein kinase catalytic subunit $\alpha$. Interestingly, a number of proteins were present only in the sham or MI group. For example, UBR3, cAMP-dependent protein kinase type II- $\alpha$ regulatory subunit (PRKAR2 $\alpha$ ), A-kinase anchor protein 1 (AKAP1, mitochondrial), and Junctophilin-2 (JPH2) were expressed only in the sham group. These genes were primarily involved in inflammatory response, microtubule binding and protease binding. Dozens of the proteins were related to cellular components. ATP5G2, calcium-transporting ATPase, COX11, adrenodoxin oxidoreductase and MUL1 were expressed in the MI group only. Some of the proteins that were present in the MI group are subunits of the mitochondrial respiratory chain complex. The 'presence' difference between the sham and MI groups indicated that mitochondrial proteome disturbance was extensive and distinct as early as minutes after MI occurrence.

To the best of our knowledge, there are no studies that have elucidated the relationship between vasopressin-regulated water reabsorption, dopaminergic synapses, peroxisomes and MI. Studies regarding the relevance of Parkinson's disease, non-alcoholic fatty liver disease and prion diseases to MI are lacking. Platelet activation, coagulation dysfunction and abnormal glucose metabolism may be involved in MI. THBS1, involved in coagulation dysfunction, also underwent the most substantial changes. The link between these pathways and MI remains to be fully elucidated and requires further investigation. Interestingly, OXPHOS, the HIF-1 signaling pathway, pentose 
phosphate pathway and PPAR signaling pathway are closely related to electron transport and energy metabolism, suggesting that the disorder of energy metabolism in cardiomyocytes is the initial pathophysiological feature of acute MI (30-32).

Mitochondrial adaptation plays a vital role in protecting key cellular components from ischemic damage. In addition, this is the main entry point for electrons to enter the process of OXPHOS, and is helpful in establishing the proton gradient needed for a large number of cells to synthesize ATP (33-34). Complex I (ubiquinone oxidoreductase) is the largest complex of the mitochondrial respiratory chain, which is composed of $>40$ subunits and is located in the mitochondrial inner membrane. Mutations that lead to complex I defects are the most common cause of neurodegeneration, myopathies and heart failure (35-37). Complex I is the most vulnerable enzyme, and the first to be damaged (38). The most common diagnosis in patients with energy production disorders is complex I activity deficiency (39). NDUFS6 is a highly conserved subunit of complex I $(40,41)$. NDUFS4 and NDUFS6 are crucial to the final step of complex I assembly and may provide a connection point for the integration of other subunits (42). Knockout of the NDUFS6 gene can lead to complex I instability and functional defects (43). The deletion of NDUFS6 increases ROS production and damages mitochondria through complex I deficiency (44). A previous study established NDUFS6 ${ }^{\mathrm{g} / \mathrm{gt}}$ mice with complex I deficiency, which revealed decreased NDUFS6 protein expression levels (43). The mice developed cardiomyopathy and heart failure. Isolated heart studies have shown that resting contractile function is severely impaired even in NDUFS6 $6^{\text {gt/gt }}$ mice without heart failure. UQCRC1 is a subunit of complex III in the respiratory chain, is encoded by nuclear DNA and consists of 480 amino acids (45-48). Disrupting one UQCRC1 allele resulted in decreased UQCRC1 mRNA and protein expression in mice. In addition, complex III formation, activity, and ATP content were decreased in the brain at baseline. Under ischemic conditions, the brain tissue showed decreased MMP and ATP content as well as increased free radical levels compared with wild-type mice. These results indicated that UQCRC1 plays a key role in complex III (49-51). Overexpression of UQCRC1 can enhance the activity of complex III in mice (52). Specific loss of UQCRC1 in cells of epithelial origin can lead to mitochondrial dysfunction. The overexpression of UQCRC1 helps to maintain the mitochondrial function of $\mathrm{H} 9 \mathrm{C} 2$ cells and regulates apoptosis-related proteins by mediating the PI3K/Akt/GSK-3b pathway to protect $\mathrm{H} 9 \mathrm{C} 2$ cells from simulated ischemia/reperfusion injury (53). These studies suggest that UQCRC1 plays an important role in mitochondrial function, and may have a protective effect on cardiomyocytes. In the present study, short-term cardiac ischemia caused significant upregulation of NDUFS6 and UQCRC1 compared with the sham group. This might be compensatory regulation for protecting the heart from metabolic dysfunction due to mitochondrial injury. COX consists of 13 subunits; the subunits COX I, COX II and COX III are encoded by mitochondrial DNA (54-56). COX11 is an endogenous mitochondrial membrane protein that is essential for the assembly of active COX $(57,58)$. The ATP synthase F (0) complex consists of subunits C1 (ATP5G1), C2 (ATP5G2) and C3 (ATP5G3) (59). A previous study identified a substantial increase in ATP5G1 in a rat model of ischemic heart failure (60). Only ATP5G2 was identified in the hearts of the ischemic mice. However, its effect on mitochondrial hemostasis needs to be further elucidated.

In conclusion, comprehensive and significant mitochondrial proteomic changes occurred after a short period of acute MI. However, the screened proteins should be confirmed by parallel reaction monitoring. Due to the limited output of mitochondrial protein in one mouse heart, the differential proteins will be validated by ELISA and/or PCR in blood samples in the future. There are still other limitations in the present study; for example, detection of serum CKMB level is necessary for confirming establishment of the MI model and will enrich the data. Among the differentially expressed proteins, the mitochondrial respiratory chain protein is the major focus of our lab. These differential proteins are involved in cellular component, oxidative phosphorylation and ubiquitination, which may regulate the post-translational modification of mitochondrial proteins. Illustrating their downstream effects and possible molecular mechanisms by overexpression/knockdown, western blotting, co-immunoprecipitation and confocal microscopy analysis in a hypoxic cardiomyocyte model will be performed in our future studies.

In conclusion, short-term acute ischemia can result in apparent cardiac mitochondrial damage and extensive disturbances to the proteome. A series of altered proteins are closely correlated with the pathways involved in OXPHOS, complement activation and mitochondrial autophagy. The results of the present study showed that mitochondrial changes may be regarded as biomarkers of the very early stages of ischemic cardiac injury. In addition, this study provides novel insights into the mechanism of myocardial remodeling targeting the mitochondrial proteome.

\section{Acknowledgements}

We would like to thank Miss Yipin Han (Bloomberg School of Public Health, Department of Epidemiology-Cardiovascular and Clinical Epidemiology, Johns Hopkins University, Baltimore USA) and Mr. Mewand Khan (School of Clinical Medicine, Ningxia Medical University, Yinchuan, Ningxia, China) for their suggestions and discussions.

\section{Funding}

This study was supported by the National Natural Science Foundation (grant no. 81660045) and Ningxia Natural Science Foundation (grant no. 2020AAC02037).

\section{Availability of data and materials}

Additional details regarding the LC-MS/MS analysis are available in the public database proteomecentral.proteomexchange. org/cgi/GetDataset? (accession no. PXD026207; Email: lingfeng_zeng@163.com, Password: sUdIhJj4). The datasets used and/or analyzed during the current study are also available from the corresponding author on reasonable request.

\section{Authors' contributions}

JW and JH confirm the authenticity of all the raw data. JW and YF collected the tissues, prepared the specimens, 
and performed the western blotting and statistical analysis. QL and FX extracted the mitochondria and performed the western blotting. JW, RH and RY established the mouse model. JH and JW designed the experiments. JW and $\mathrm{JH}$ wrote the manuscript. All authors have read and approved the final manuscript.

\section{Ethics approval and consent to participate}

All experiments and procedures were approved by the Institutional Animal Care and Use Committee Review Board of the General Hospital of Ningxia Medical University (approval no. 2020-01) and complied with the guidelines of the National Institutes of Health Animal Care and Use Committee.

\section{Patient consent for publication}

Not applicable.

\section{Competing interests}

The authors declare that they have no competing interests.

\section{References}

1. Farthing DE, Farthing CA and Xi L: Inosine and hypoxanthine as novel biomarkers for cardiac ischemia: From bench to point-of-care. Exp Biol Med (Maywood) 240: 821-831, 2015.

2. Shvedova M, Anfinogenova Y, Atochina-Vasserman EN, Schepetkin IA and Atochin DN: c-Jun N-terminal kinases (JNKs) in myocardial and cerebral ischemia/reperfusion injury. Front Pharmacol 9: 715, 2018.

3. Oyama Y, Bartman CM, Gile J, Sehrt D and Eckle T: The circadian PER2 enhancer nobiletin reverses the deleterious effects of midazolam in myocardial ischemia and reperfusion injury. Curr Pharm Des 24: 3376-3383, 2018.

4. Škrlec I, Milić J and Steiner R: The impact of the circadian genes CLOCK and ARNTL on myocardial infarction. J Clin Med 9 484, 2020.

5. Pavo N, Lukovic D, Zlabinger K, Zimba A, Lorant D, Goliasch G, Winkler J, Pils D, Auer K, Jan Ankersmit H, et al: Sequentia activation of different pathway networks in ischemia-affected and non-affected myocardium, inducing intrinsic remote conditioning to prevent left ventricular remodeling. Sci Rep 7: 43958, 2017.

6. Ruiz-Meana M, Abellán A, Miró-Casas E and Garcia-Dorado D Opening of mitochondrial permeability transition pore induces hypercontracture in $\mathrm{Ca}^{2+}$ overloaded cardiac myocytes. Basic Res Cardiol 102: 542-552, 2007.

7. Santos-Gallego CG, Vahl TP, Goliasch G, Picatoste B, Arias T, Ishikawa K, Njerve IU, Sanz J, Narula J, Sengupta PP, et al: Sphingosine-1-phosphate receptor agonist fingolimod increases myocardial salvage and decreases adverse postinfarction left ventricular remodeling in a porcine model of ischemia/reperfusion. Circulation 133: 954-966, 2016.

8. Saito T, Nah J, Oka SI, Mukai R, Monden Y, Maejima Y, Ikeda Y, Sciarretta S, Liu T, Li H, et al: An alternative mitophagy pathway mediated by Rab9 protects the heart against ischemia. J Clin Invest 129: 802-819, 2019.

9. Jacquet S, Yin X, Sicard P, Clark J, Kanaganayagam GS, Mayr M and Marber MS: Identification of cardiac myosin-binding protein $\mathrm{C}$ as a candidate biomarker of myocardial infarction by proteomics analysis. Mol Cell Proteomics 8: 2687-2699, 2009.

10. Kim N, Lee Y, Kim H, Joo H, Youm JB, Park WS, Warda M, Cuong DV and Han J: Potential biomarkers for ischemic heart damage identified in mitochondrial proteins by comparative proteomics. Proteomics 6: 1237-1249, 2006.

11. Wu J, Zhang Y, Wu Q, Xie D, Dai W, Zhang X, Yang Z and Wang D: Integrative analyses of myocardial lipidome and proteome implicate mitochondrial dysfunction in lethal ventricular tachyarrhythmia (LVTA) induced by acute myocardial ischemia (AMI). J Proteomics 197: 14-22, 2019.
12. Cao TH, Jones DJL, Voors AA, Quinn PA, Sandhu JK, Chan DC, Parry HM, Mohan M, Mordi IR, Sama IE, et al: Plasma proteomic approach in patients with heart failure: Insights into pathogenesis of disease progression and potential novel treatment targets. Eur J Heart Fail 22: 70-80, 2020.

13. Wang Y, LiC, Chuo W, Liu Z, Ouyang Y, Li D, Han J, Wu Y, Guo S and Wang W: Integrated proteomic and metabolomic analysis reveals the NADH-mediated TCA cycle and energy metabolism disorders based on a new model of chronic progressive heart failure. Mol Biosyst 9: 3135-3145, 2013.

14. Zhang G, Zhou B, Zheng Y, Feng K, Rao L, Zhang J, Xin J, Zhang $B$ and Zhang L: Time course proteomic profile of rat acute myocardial infarction by SELDI-TOF MS analysis. Int J Cardiol 131: 225-233, 2009.

15. Gao E and Koch WJ: A novel and efficient model of coronary artery ligation in the mouse. Wound Regeneration and Repair. Springer, Clifton, NJ, pp299-311, 2013.

16. Lu L, Ma J, Sun M, Wang X, Gao E, Lu L, Ren J, Yang L and Yang J: Melatonin ameliorates MI-induced cardiac remodeling and apoptosis through a JNK/p53-dependent mechanism in diabetes mellitus. Oxid Med Cell Longev 2020: 1535201, 2020.

17. Chen J, Ceholski DK, Liang L, Fish K and Hajjar RJ: Variability in coronary artery anatomy affects consistency of cardiac damage after myocardial infarction in mice. Am J Physiol Heart Circ Physiol 313: H275-H282, 2017.

18. Flameng W, Borgers M, Daenen W and Stalpaert G: Ultrastructural and cytochemical correlates of myocardial protection by cardiac hypothermia in man. $\mathrm{J}$ Thorac Cardiovasc Surg 79: 413-424, 1980

19. Wang W, Zhou X, Cui F, Shi C, Wang Y, Men Y, Zhao W and Zhao J: Proteomic analysis on exosomes derived from Patients' sera infected with Echinococcus granulosus. Korean J Parasitol 57: 489-497, 2019

20. Wang L, Huang Y, Wang X and Chen Y: Label-free LC-MS/MS proteomics analyses reveal proteomic changes accompanying MSTN KO in C2C12 cells. BioMed Res Int 2019: 7052456, 2019.

21. Cox J, Neuhauser N, Michalski A, Scheltema RA, Olsen JV and Mann M: Andromeda: A peptide search engine integrated into the MaxQuant environment. J Proteome Res 10: 1794-1805, 2011.

22. Ashburner M, Ball CA, Blake JA, Botstein D, Butler H, Cherry JM, Davis AP, Dolinski K, Dwight SS, Eppig JT, et al; The Gene Ontology Consortium: Gene ontology: Tool for the unification of biology. Nat Genet 25: 25-29, 2000.

23. The Gene Ontology Consortium: The Gene Ontology Resource: 20 years and still GOing strong. Nucleic Acids Res 47: D330-D338, 2019.

24. Kanehisa M: Post-Genome Informatics. Oxford University Press, Oxford, NY, 2000

25. van Bilsen M, Smeets PJ, Gilde AJ and van der Vusse GJ: Metabolic remodelling of the failing heart: The cardiac burn-out syndrome? Cardiovasc Res 61: 218-226, 2004.

26. Brown DA, Perry JB, Allen ME, Sabbah HN, Stauffer BL, Shaikh SR, Cleland JG, Colucci WS, Butler J, Voors AA, et al: Expert consensus document: Mitochondrial function as a therapeutic target in heart failure. Nat Rev Cardiol 14: 238-250, 2017.

27. Davidson MT, Grimsrud PA, Lai L, Draper JA, Fisher-Wellman KH, Narowski TM, Abraham DM, Koves TR, Kelly DP and Muoio DM: Extreme acetylation of the cardiac mitochondrial proteome does not promote heart failure. Circ Res 127: 1094-1108, 2020.

28. Frangogiannis NG: Pathophysiology of myocardial infarction. Compr Physiol 5: 1841-1875, 2015.

29. Kolb AL, Corridon PR, Zhang S, Xu W, Witzmann FA, Collett JA, Rhodes GJ, Winfree S, Bready D, Pfeffenberger ZJ, et al: Exogenous gene transmission of isocitrate dehydrogenase 2 mimics ischemic preconditioning protection. J Am Soc Nephrol 29: 1154-1164, 2018.

30. Gentillon C, Li D, Duan M, Yu WM, Preininger MK, Jha R, Rampoldi A, Saraf A, Gibson GC, Qu CK, et al: Targeting HIF-1 $\alpha$ in combination with PPAR $\alpha$ activation and postnatal factors promotes the metabolic maturation of human induced pluripotent stem cell-derived cardiomyocytes. J Mol Cell Cardiol 132: 120-135, 2019.

31. Wu J, Chen P, Li Y, Ardell C, Der T, Shohet R, Chen M and Wright GL: HIF-1 $\alpha$ in heart: Protective mechanisms. Am J Physiol Heart Circ Physiol 305: H821-H828, 2013.

32. Gibb AA, Lorkiewicz PK, Zheng YT, Zhang X, Bhatnagar A, Jones SP and Hill BG: Integration of flux measurements to resolve changes in anabolic and catabolic metabolism in cardiac myocytes. Biochem J 474: 2785-2801, 2017. 
33. Smeitink JA, Zeviani M, Turnbull DM and Jacobs HT: Mitochondrial medicine: A metabolic perspective on the pathology of oxidative phosphorylation disorders. Cell Metab 3: 9-13, 2006.

34. Tucker EJ, Compton AG, Calvo SE and Thorburn DR: The molecular basis of human complex I deficiency. IUBMB Life 63: 669-677, 2011.

35. Severs NJ, Bruce AF, Dupont E and Rothery S: Remodelling of gap junctions and connexin expression in diseased myocardium. Cardiovasc Res 80: 9-19, 2008.

36. Tsutsui H, Ide T and Kinugawa S: Mitochondrial oxidative stress, DNA damage, and heart failure. Antioxid Redox Signal 8: 1737-1744, 2006

37. Elurbe DM and Huynen MA: The origin of the supernumerary subunits and assembly factors of complex I: A treasure trove of pathway evolution. Biochim Biophys Acta 1857: 971-979, 2016.

38. Triepels RH, Van Den Heuvel LP, Trijbels JM and Smeitink JA: Respiratory chain complex I deficiency. Am J Med Genet 106 37-45, 2001.

39. Forbes JM, Ke BX, Nguyen TV, Henstridge DC, Penfold SA, Laskowski A, Sourris KC, Groschner LN, Cooper ME, Thorburn DR, et al: Deficiency in mitochondrial complex I activity due to Ndufs 6 gene trap insertion induces renal disease. Antioxid Redox Signal 19: 331-343, 2013.

40. Kmita K, Wirth C, Warnau J, Guerrero-Castillo S, Hunte C, Hummer G, Kaila VR, Zwicker K, Brandt U and Zickermann V: Accessory NUMM (NDUFS6) subunit harbors a Zn-binding site and is essential for biogenesis of mitochondrial complex I. Proc Natl Acad Sci USA 112: 5685-5690, 2015.

41. Lazarou M, McKenzie M, Ohtake A, Thorburn DR and Ryan MT: Analysis of the assembly profiles for mitochondrialand nuclear-DNA-encoded subunits into complex I. Mol Cell Biol 27: 4228-4237, 2007.

42. Zhang Y, Guo L, Han S, Chen L, Li C, Zhang Z, Hong Y, Zhang X, Zhou X, Jiang D, et al: Adult mesenchymal stem cel ageing interplays with depressed mitochondrial Ndufs6. Cell Death Dis 11:1075, 2020.4

43. Ke BX, Pepe S, Grubb DR, Komen JC, Laskowski A, Rodda FA Hardman BM, Pitt JJ, Ryan MT, Lazarou M, et al: Tissue-specific splicing of an Ndufs6 gene-trap insertion generates a mitochondrial complex I deficiency-specific cardiomyopathy. Proc Natl Acad Sci USA 109: 6165-6170, 2012.

44. Schulte U, Arretz M, Schneider H, Tropschug M, Wachter E, Neupert W and Weiss H: A family of mitochondrial proteins involved in bioenergetICS and biogenesis. Nature 339: 147-149, 1989

45. Shan W, Li J, Xu W, Li H and Zuo Z: Critical role of UQCRC1 in embryo survival, brain ischemic tolerance and normal cognition in mice. Cell Mol Life Sci 76: 1381-1396, 2019.

46. Unni S, Thiyagarajan S, Srinivas Bharath MM and Padmanabhan B: Tryptophan oxidation in the UQCRC1 subunit of mitochondrial complex III (Ubiquinol-Cytochrome C Reductase) in a mouse model of myodegeneration causes large structural changes in the complex: A molecular dynamics simulation study. Sci Rep 9: 10694, 2019.

47. Davis M, Whitely T, Turnbull DM and Mendelow AD: Selective impairments of mitochondrial respiratory chain activity during aging and ischemic brain damage. Brain Edema X. Springer, Berlin, pp56-58, 1997.
48. Moro MA, Almeida A, Bolaños JP and Lizasoain I: Mitochondrial respiratory chain and free radical generation in stroke. Free Radic Biol Med 39: 1291-1304, 2005.

49. Fan H, He Z, Huang H, Zhuang H, Liu H, Liu X, Yang S, He P, Yang $\mathrm{H}$ and Feng D: Mitochondrial quality control in cardiomyocytes: A critical role in the progression of cardiovascular diseases. Front Physiol 11: 252, 2020.

50. Kriaucionis S, Paterson A, Curtis J, Guy J, Macleod N and Bird A: Gene expression analysis exposes mitochondrial abnormalities in a mouse model of Rett syndrome. Mol Cell Biol 26: 5033-5042, 2006.

51. Shibanuma M, Inoue A, Ushida K, Uchida T, Ishikawa F, Mori K and Nose K: Importance of mitochondrial dysfunction in oxidative stress response: A comparative study of gene expression profiles. Free Radic Res 45: 672-680, 2011

52. Ide T, Tsutsui H, Hayashidani S, Kang D, Suematsu N, Nakamura K, Utsumi H, Hamasaki $\mathrm{N}$ and Takeshita A: Mitochondrial DNA damage and dysfunction associated with oxidative stress in failing hearts after myocardial infarction. Circ Res 88: 529-535, 2001.

53. Yi T, Wu X, Long Z, Duan G, Wu Z, Li H, Chen H and Zhou X: Overexpression of ubiquinol-cytochrome c reductase core protein 1 may protect h9c2 cardiac cells by binding with Zinc. BioMed Res Int 2017: 1314297, 2017.

54. Carr HS, Maxfield AB, Horng YC and Winge DR: Functional analysis of the domains in Cox11. J Biol Chem 280: 22664-22669, 2005.

55. Sun M, Zuo X, Li R, Wang T and Kang YJ: Vascular endothelial growth factor recovers suppressed cytochrome c oxidase activity by restoring copper availability in hypertrophic cardiomyocytes. Exp Biol Med (Maywood) 239: 1671-1677, 2014.

56. Palmer DN, Fearnley IM, Medd SM, Walker JE, Martinus RD, Bayliss SL, Hall NA, Lake BD, Wolfe LS and Jolly RD: Lysosomal storage of the DCCD reactive proteolipid subunit of mitochondrial ATP synthase in human and ovine ceroid lipofuscinoses. Adv Exp Med Biol 266: 211-223, 1989.

57. Li HS, Zhang JY, Thompson BS, Deng XY, Ford ME, Wood PG, Stolz DB, Eagon PK and Whitcomb DC: Rat mitochondrial ATP synthase ATP5G3: Cloning and upregulation in pancreas after chronic ethanol feeding. Physiol Genomics 6: 91-98, 2001

58. Liu T, Chen L, Kim E, Tran D, Phinney BS and Knowlton AA: Mitochondrial proteome remodeling in ischemic heart failure. Life Sci 101: 27-36, 2014.

59. Wadosky KM and Willis MS: The story so far: Post-translational regulation of peroxisome proliferator-activated receptors by ubiquitination and SUMOylation. Am J Physiol Heart Circ Physiol 302: H515-H526, 2012.

60. Wang Z, Wang SP, Shao Q, Li PF, Sun Y, Luo LZ, Yan XQ, Fan ZY, Hu J, Zhao J, et al: Brain-derived neurotrophic factor mimetic, 7,8-dihydroxyflavone, protects against myocardial ischemia by rebalancing optic atrophy 1 processing. Free Radic Biol Med 145: 187-197, 2019.

This work is licensed under a Creative Commons Attribution-NonCommercial-NoDerivatives 4.0 International (CC BY-NC-ND 4.0) License. 